\title{
Temperature-Dependence of the Solid-Electrolyte Interphase Overpotential: Part I. Two Parallel Mechanisms, One Phase Transition
}

\author{
Journal Article \\ Author(s): \\ Hess, Michael \\ Publication date: \\ 2018-01-27 \\ Permanent link: \\ https://doi.org/10.3929/ethz-b-000267241 \\ Rights / license: \\ Creative Commons Attribution 4.0 International \\ Originally published in: \\ Journal of the Electrochemical Society 165(2), https://doi.org/10.1149/2.0701802jes
}




\title{
(ES) \\ Temperature-Dependence of the Solid-Electrolyte Interphase Overpotential: Part I. Two Parallel Mechanisms, One Phase Transition
}

\author{
Michael Hess $\odot$ 1,2,z \\ ${ }^{I}$ Department of Electrical Engineering and Information Technology, ETH Zurich, Laboratory of Nanoelectronics, 8092 \\ Zurich, Switzerland \\ ${ }^{2}$ Battronics AG, $\beta$-research division, 8037 Zurich, Switzerland
}

It has been shown recently that the overpotential originating from ionic conduction of alkali-ions through the inner dense solidelectrolyte interphase (SEI) is strongly non-linear. An empirical equation was proposed to merge the measured resistances from both galvanostatic cycling (GS) and electrochemical impedance spectroscopy (EIS) at $25^{\circ} \mathrm{C}$. Here, this analysis is extended to the full temperature range of batteries from $-40^{\circ} \mathrm{C}$ to $+80^{\circ} \mathrm{C}$ for $\mathrm{Li}, \mathrm{Na}, \mathrm{K}$ and $\mathrm{Rb}$-metal electrodes in carbonate electrolytes. Two different transport mechanisms are found. The first one conducts alkali-ions at all measured temperatures. The second transport mechanism conducts ions for all seven measured Li-ion electrolytes and one out of four Na-ion electrolytes; however, only above a certain critical temperature $\mathrm{T}_{\mathrm{C}}$. At $\mathrm{T}_{\mathrm{C}}$ a phase transition is observed switching-off the more efficient transport mechanism and leaving only the general ion conduction mechanism. The associated overpotentials increase rapidly below $\mathrm{T}_{\mathrm{C}}$ depending on alkali-ion, salt and solvent and become a limiting factor during galvanostatic operation of all Li-ion electrolytes at low temperature. In general, the current analysis merges the SEI resistances measured by EIS ranging from $26 \Omega \mathrm{cm}^{2}$ for the best Li up to $292 \mathrm{M} \Omega \mathrm{cm}^{2}$ for Rb electrodes to its galvanostatic response over seven orders of magnitude. The determined critical temperatures are between $0-25^{\circ} \mathrm{C}$ for the tested $\mathrm{Li}$ and above $50^{\circ} \mathrm{C}$ for Na electrolytes.

(C) The Author(s) 2018. Published by ECS. This is an open access article distributed under the terms of the Creative Commons Attribution 4.0 License (CC BY, http://creativecommons.org/licenses/by/4.0/), which permits unrestricted reuse of the work in any medium, provided the original work is properly cited. [DOI: 10.1149/2.0701802jes]

(cc) BY

Manuscript submitted September 21, 2017; revised manuscript received December 14, 2017. Published January 27, 2018.

Extensive research over the last thirty years on Li-ion batteries (LIB) has advanced the field so that LIBs do not only power electronic gadgets anymore as in the 1990's but are also starting to drive new transportation systems like electric bikes, cars and buses. However, in transportation performance at different temperatures is far more relevant especially during recharge.

Recently, it was shown that the overpotential originating from the solid-electrolyte interphase (SEI) is strongly non-linear. ${ }^{1,2}$ At ambient temperature, this overpotential is negligible for Li-metal in alkylcarbonate solvents, however, severe for $\mathrm{Na}$ and $\mathrm{K}$-metal electrodes. The resistances from both, electrochemical impedance spectroscopy (EIS) and short galvanostatic charge and discharges (GS) could be fit with the same parameter set by introducing an empirical equation. ${ }^{1}$

However, that publication focused exclusively on standard conditions of ambient temperature and fixed concentrations of solvents and salts commonly used in research. ${ }^{1}$ Naturally, the problem needs to be investigated at different conditions including temperature $T$, pressure, and concentration $c$ of various species within the system. While the influence of concentration is rather of interest for patents, temperature dependence is both, crucial for academic understanding and for industrial application.

Very precise measurements of the SEI resistance have been published using EIS. These resistances vary for different $\mathrm{Li}$ salts and solvents usually between 40 to $100 \Omega \mathrm{cm}^{2} .{ }^{1,3-6} \mathrm{In}$ contrast, for Nametal electrodes these SEI resistances rise already to $230-670 \Omega \mathrm{cm}^{2}$, while they reach $3500 \Omega \mathrm{cm}^{2}$ for $0.5 \mathrm{M} \mathrm{KPF}_{6}$ in EC:DMC $1: 1 .^{1}$ In contrast, galvanostatic cycling of the $\mathrm{K}$-system is possible up to current densities of $56 \mathrm{mAcm}^{-2},{ }^{1}$ with as little as $1.5 \mathrm{~V}$ total overpotential from both electrodes. If one would assume linear ohmic resistance for the SEI as often applied in modeling, ${ }^{7}$ an overpotential of incredible $196 \mathrm{~V}(3500 \times 0.056)$ would be expected instead of the measured 1.5 $\mathrm{V}$. Thus, SEI resistance is clearly not of ohmic character.

In the 1980's and beginning of 1990's, intense research has been focused on the SEI, also with regard to its overpotential. Many studies concentrated on the system of $\mathrm{LiAlCl}_{4}$ in $\mathrm{SOCl}_{2}$ solvent leading to a very thick SEI layer on the Li-metal electrode due to the highly re-

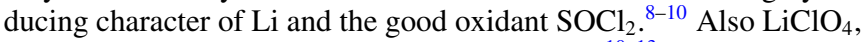
$\mathrm{LiAsF}_{6}$, and $\mathrm{LiBF}_{4}$ in $\mathrm{PC}$, and $\gamma$-butyrolactone ${ }^{10-13}$ have been analyzed. For these systems two different models of ionic conduction

${ }^{\text {z} E-m a i l: ~ m i c h a e l @ b a t t r o n i c s . c o m ~}$ based on Young's equation ${ }^{14,15}$ and space-charge limited current ${ }^{10,13}$ have been successfully applied. However, it was not possible to fit the SEI overpotential of $\mathrm{Li}, \mathrm{Na}$, and $\mathrm{K}$ electrodes at ambient temperature in several different carbonate systems with neither of the two proposed models. ${ }^{1}$

Looking into literature, the space-charge limited model ${ }^{10}$ was already disqualified by the same authors in their temperature-dependent data in plot 3 of Ref. 13. They showed a power-law-dependence with the exponent ranging from 2.5 for their $70^{\circ} \mathrm{C}$ data up to 4.5 at $-35^{\circ} \mathrm{C}$ while they expected a power law dependence of two. While Churikov extended the model to a temperature-dependent exponent to fit the data, ${ }^{13}$ one has to mention, that a power law is not expected in electrochemistry as most equations are based on the Euler number (ButlerVolmer, Nernst, Arrhenius, conduction in concentrated electrolytes). ${ }^{7}$

The Young equation seems to be the most prominent and is cited throughout literature from its development in $1961^{14}$ to its proposition for the SEI in $1979^{16}$ and through SEI research and reviews up to today. ${ }^{6,17}$ The equation by Young has the form $\mathrm{i}=$ prefactor $\cdot \sinh (\mathrm{zF} / \mathrm{RT} \cdot \mathrm{a} / \mathrm{d} \cdot \eta)^{14}$ with $a$ being the half-jump distance and $d$ the thickness of the film which is intended to describe the hopping of ions through Frenkel and Schottky defects. ${ }^{14}$ One can simply challenge the validity of this equation by its limits. If we assume no defects at all, $a$ is $0.5 \mathrm{~d}$ so ions hop through the whole SEI and the Young equation becomes the Butler-Volmer equation. When we assume infinite many defects, $a$ becomes 0 and the needed overpotential approaches infinite to drive at least a certain current. Thus, the more defects we have the higher the needed overpotential up to infinity for a very defect-rich SEI. This is clearly in contrast to general observations where we observe better hopping and conduction if sites are closer together and seems to be due to the fact that the half-jump distance might not be the correct parameter to use.

Additionally, since $a$ is always smaller than $0.5 \mathrm{~d}$, the lowest overpotential we could expect is a Bulter-Volmer equation and as soon as defects are introduced more overpotential is needed. Thus, in LIB research, the SEI overpotential would have been a dominant contribution during galvanostatic experiments as it would have always been higher than any charge-transfer reaction of Butler-Volmer type. Thus, also the Young equation cannot be used to describe ionic transport in the SEI or would need to be modified.

To get more insight into the overpotentials associated with the ionic conduction through the SEI, here, temperature dependence is 
investigated. The results of $\mathrm{Li}, \mathrm{Na}, \mathrm{K}$ and $\mathrm{Rb}$-metal electrodes are compared to literature values and dissected into their underlying conduction mechanisms.

\section{Experimental}

Dry Li-foil (Alfa Aeser, 99.9\%), dry Na-rods (Acros, 99.8\%), K-cubes in mineral oil (Aldrich, 99.5\%) and Rb-metal in ampoules (Strem, $99.9+\%$ ) have been cleaned from oxidation layers and used to prepare $13 \mathrm{~mm}$ diameter electrodes. Symmetrical alkali vs. alkali cells were prepared in an Argon filled glove box with continuous removal of $\mathrm{O}_{2}, \mathrm{H}_{2} \mathrm{O}$ and organic volatiles being usually $<0.1 \mathrm{ppm}$. However, Kmetal and especially $\mathrm{Rb}$ oxidized very quickly forming a purple $(\mathrm{K})$ to blue $(\mathrm{Rb})$ surface layer within a minute and few seconds, respectively, before cell assembly could be finished. Cs electrodes were impossible to prepare in the glove box due to its low melting point of $28.4^{\circ} \mathrm{C}$.

Ethylene carbonate EC (Aldrich, anhydrous 99\%), propylene carbonate PC (Aldrich, anhydrous 99.7\%), and dimethyl-carbonate DMC (Acros, extradry 99+\%) were additionally dried over $4 \AA$ molecular sieves for at least six weeks after which $16 \mathrm{ppm}$ of trace water was still present measured by Karl-Fischer-Titration. Electrolytes for Li were purchased in prepared state being $1 \mathrm{M} \mathrm{LiPF}_{6}$ in EC:DMC 1:1 wt (Novolyte/BASF).

The salts $\mathrm{LiPF}_{6}$ (Strem Chemicals, 99.9+\%), $\mathrm{LiClO}_{4}$ (Aldrich, ampoule $99.99 \%$ ), Li-bis(oxalato)borate LiBOB (Aldrich), Li-bistri fluoromethanesulfonimidate LiTFSI (Aldrich, 99.95\%), $\mathrm{NaPF}_{6}$ (Alfa Aesar, 99+\%), $\mathrm{NaClO}_{4}$ (Acros, 99+\%), $\mathrm{KPF}_{6}$ (Strem Chemicals, 99.5\%), $\mathrm{KClO}_{4}$ (Acros, 99\%) and $\mathrm{RbClO}_{4}$ (Strem, 99.9\%) were vacuum dried at $25^{\circ} \mathrm{C}$ for one day before use. The solvents were prepared in weight equivalent mixtures. The salt was added based on the calculated density of the pure solvent mixture without the salt leading to a systematic error of circa 3-4\% lower molarity than 1 M (see Suppl. Note 1).

Whatman glass microfiber filters (GE Healthcare, GF/D 1823257) were heated inside the glove box to $400^{\circ} \mathrm{C}$ to remove adsorbed water and are used due to their very high porosity of circa $86-88 \%$ after compression to circa $430 \mu \mathrm{m}$ at $\mathrm{p}=50 \mathrm{Ncm}^{-2}$ in the coin type cells made from titanium (please note error in reported porosity and thickness of GF separator in Ref. 1). Galvanostatic cycling (GS) and electrochemical impedance spectroscopy (EIS) were performed with Biologic VMP3 and MPG2 cyclers from temperatures ranging from -40 to $+80^{\circ} \mathrm{C}$ for GS and -40 to $25^{\circ} \mathrm{C}$ for EIS. The maximum allowed overpotential of the cell was $4.5 \mathrm{~V}$ to avoid SEI oxidation at the dissolving alkali-metal electrode. More details can be found in Suppl. Note 1.

Experimental limitations are given by solubility limits of $\mathrm{Na} / \mathrm{K}-\mathrm{PF}_{6}$ in EC:DMC 1:1wt ${ }^{18}$ and K/Rb-ClO4 in both EC:DMC and PC. Usually, the maximum solubility of a particular salt in a solvent at $25^{\circ} \mathrm{C}$ was not prepared to avoid early salt precipitation at lower temperatures. Additionally, the melting point of alkali-metals of $T_{m}=63.5^{\circ} \mathrm{C}$ for $\mathrm{K}$ and $T_{m}=39.5^{\circ} \mathrm{C}$ for Rb limited the upper operation temperature for $\mathrm{K} / \mathrm{Rb}$ cells. The lower operation temperature of EC:DMC $1: 1 \mathrm{wt}$ mixtures was also limited where the electrolytes operated last at $-20^{\circ} \mathrm{C}$ for $1 \mathrm{M} \mathrm{LiPF}_{6},-30^{\circ} \mathrm{C}$ for $1 \mathrm{M} \mathrm{LiClO}_{4}, 1 \mathrm{M} \mathrm{LiTFSI}$ and $0.5 \mathrm{M}$ $\mathrm{NaPF}_{6}$, and only until $-10^{\circ} \mathrm{C}$ for $1 \mathrm{M} \mathrm{NaClO}_{4}, 0.5 \mathrm{M} \mathrm{KPF}_{6}$ and 0.05 $\mathrm{M} \mathrm{KClO}_{4}$ all in EC:DMC 1:1wt, while all electrolytes containing PC operated nicely until $-40^{\circ} \mathrm{C}$ due to its low $T_{m}$ of $-48.8^{\circ} \mathrm{C} .{ }^{19}$ These are the hard bounds while further soft limitations will be given in the Results section.

\section{Results}

The measured GS and EIS data are analyzed based on the three transport processes of charge transfer reactions, ionic conduction in the electrolyte and ionic conduction within the inner dense SEI. These three transport processes will be modeled by the Butler-Volmer equation (Eq. 1), Ohms law (Eq. 2) and the empirical equation proposed earlier (Eq. 3). ${ }^{1,2}$ While Butler-Volmer and Ohms law are commonly used equations the third empirical equation by Hess $^{1}$ does not normalize the overpotential over $25.6 \mathrm{mV}$ at $25^{\circ} \mathrm{C}$ but introduces a muting factor $\mathrm{H}$ in the exponent, thus, making the saturation potential variable. The following three equations are used for the current analysis:

$$
\begin{gathered}
j_{\text {ButVol }}=j_{0, B V}\left(e^{0.5 \frac{z F}{R T} \eta_{B V}}-e^{-0.5 \frac{z F}{R T} \eta_{B V}}\right) \\
j_{\text {Ohm }}=\eta_{\text {Ohm }} /_{A R_{O h m}} \text { where } R_{\text {Ohm }}=R_{\text {elyte }} \cdot \tau_{\text {sep }} / \varepsilon_{\text {sep }} \\
j_{\text {Hess }}=j_{0, H}\left(e^{0.5 \frac{z F}{R T} \eta_{H} \cdot H}-e^{-0.5 \frac{z F}{R T} \eta_{H} \cdot H}\right)
\end{gathered}
$$

with the parameters current densities $j$, exchange current densities $j_{0, B V}$ and $j_{O, H}$, overpotentials $\eta_{x}$, ohmic resistance $R_{O h m}$, the muting factor $H$, Faraday constant $F$, gas constant $R$, and the temperature $T$. One needs to assume that all three processes are in series so that $j_{B V}=j_{O h m}=$ $j_{\text {Hess }}$ meaning the overpotentials are additive. This assumption is valid as long as all current passes through all processes and all processes are sufficiently homogeneous over the alkali electrode to average them macroscopically. Additionally, all kinetics are neglected, e.g. double layer capacitance variations, SEI reforming processes and the geometric surface area is used neglecting dendrite growth and surface roughness.

To allow comparison between EIS and GS cycling, the limit of the equations of Butler-Volmer, Ohm and Hess for very small excitations can be derived as follows: ${ }^{1}$

$$
\begin{gathered}
R_{B V}\left(\eta_{B V}<<\frac{R T}{F}\right)=\frac{\eta_{B V}}{j A}=\frac{R T}{F A} \frac{1}{j_{0, B V}} \\
R_{O h m}=\frac{\eta_{\text {Ohm }}}{j A}=\frac{\tau_{\text {sep }}}{\varepsilon_{\text {sep }}} R_{\text {elyte }}=\frac{\tau_{\text {sep }}}{\varepsilon_{\text {sep }}} \frac{A}{\kappa l} \\
R_{H}\left(\eta_{H}<<\frac{R T}{F H}\right)=\frac{\eta_{H}}{j A}=\frac{R T}{F A} \frac{1}{j_{0, H} H}
\end{gathered}
$$

Fitting of galvanostatic data is based on Matlab's LevenbergMarquard method in the function "fit" by Mathworks. For the three transport equations in Eqs. 1 to 3, the four parameters $j_{0, B V}, R_{O h m}, H$ and $j_{0, H}$ are fit as constants for a given current-density to voltage plot. Thus, the system is over-determined and cannot be solved analytically but is fit to minimize a weighted least-square cost function. The sum of the three overpotentials $\eta_{x}$ of the three processes at each given current density $j=j_{B V}=j_{O h m}=j_{\text {Hess }}$ are compared to the experimental overpotential and the difference is minimized. Detailed information of the fitting procedure and the error bars can be found in SI notes 3, 5 and 6 .

Error analysis and sensitivity.-It is important to note that the equations of Butler-Volmer and Hess (Eqs. 1 and 3) and their limit for small excitations (Eqs. 4 and 6) are the same if the muting factor $H$ approaches the value of 1 . Thus, the parameters $j_{O, B V}$ and $j_{O, H}$ of both equations can become interchangeable and can lead to errors in the parameter estimation in case of values of $H$ around unity.

Additionally, the analysis of alkali-metal electrodes is usually influenced by several different mechanisms that change the parameters of the underlying reaction and transport mechanisms. All alkali-metal electrodes $\mathrm{Li}, \mathrm{Na}, \mathrm{K}$ and $\mathrm{Rb}$ undergo dendrite formation during metal deposition while they show no significant pitting but rather a homogeneous dissolution on the counter electrode during galvanostatic cycling (e.g. Suppl. Videos of Ref. 20). This leads to surface area increases and most probably a thinner newly formed SEI layer on the deposition electrode only. Additionally, symmetric cells of these alkali metals cannot account for asymmetries in both the charge transfer reaction and ionic conduction within the SEI. Thus, using an asymmetry coefficient $\alpha=0.5$ of the charge transfer reaction and SEI overpotential and dividing the total overpotential of symmetric cells simply by a factor of two to account for both electrodes is a very questionable 
and probably wrong assumption. However, no further information on neither the asymmetry parameters nor the real active surface area can be determined precisely without the help of e.g. reference electrodes.

To minimize the effect of surface area increase, only short galvanostatic pulses of $7 \mathrm{mAhcm}^{-2}$ have been applied depositing circa $3.4 \mu \mathrm{m}\left(0.18 \mathrm{mgcm}^{-2}\right)$ in the case of Li. Each high current density charge/discharge was followed by a low current density discharge/charge, respectively, to smooth out any formed dendrites. However, the newly built SEI on the freshly deposited alkali electrode will contribute to the systematic error of this analysis as it might be thinner and less crystalline. Thus, all following evaluations in this manuscript should be seen in the light that alkali-metal electrodes behave asymmetric, but here, need to be evaluated as if deposition and dissolution are symmetric.

In contrast to the previous publication where at least five nominally equal cells have been tested for each configuration to allow statistics, ${ }^{1}$ here, usually only one sample was tested due to the limitations of the climate chamber. Only samples at important temperatures have been repeated up to a maximum of four times to get certain statistics.

The second challenge is the sensitivity of the three transport processes and their individual contribution to both the GS and EIS experiments. In general, the ohmic resistance of the electrolyte can be well extracted from both the GS and EIS data as it is very sensitive to high current densities during GS and the real axis intercept at infinite frequency during EIS. One just needs to note that the transference number is $0.4-0.56$ for the GS case depending on the separator ${ }^{21,22}$ and 1 in the case of EIS as both anions and cations conduct the current in the limit of infinite frequency.

The charge transfer reaction modeled by the Butler-Volmer equation is the least sensitive parameter. During GS cycling $j_{0, B V}$ can be mainly fitted to high current density data where both dendrite growth and surface area increase contribute the most. Additionally, the usually high exchange current densities of metals and here also alkali-metals make this process rather not limiting, so not very sensitive to small changes. Also the resulting EIS resistances for small excitations in Eq. 4 show that the charge-transfer resistance is rather small compared to the SEI resistance and cannot be extracted from EIS data. ${ }^{1}$ Thus, only the GS data at high current density can be used; however, will result in large error bars as shown later. This insensitivity could explain why the exchange current density $j_{O, B V}$ varies over several orders of magnitude in literature (e.g. Table 1 in Ref. 23) for similar electrolytes.

The third process concerns the ionic conductivity of the SEI. During GS cycling this process is sensitive giving the smallest error bars for $j_{0, H}$ and medium error bars for $H$ as they can be determined at very low and medium current density, respectively. Also during EIS the combination of $j_{0, H}$ and $H$ in Eq. 6 is very sensitive as it represents the first semi-circle in the Nyquist plots. However, the individual parameters can only be separated during GS experiments as shown earlier. ${ }^{1}$

Analysis procedure.-Examples of short galvanostatic cycling experiments at various current densities are displayed in Figure 1 for 1 $\mathrm{M} \mathrm{LiPF}_{6}$ in EC:DMC at $-10,30$ and $70^{\circ} \mathrm{C}$. At $-10^{\circ} \mathrm{C}$ one can see salt depletion at very high current density of $56 \mathrm{mAcm}^{-2}$ which is double the calculated limiting current density of the system. ${ }^{1}$ To guarantee similarity of the different electrodes first two high current density activation discharges have been performed to exchange the native passivation layer on alkali metals.

An interesting feature is the overshoot in the beginning of all current densities at $-10^{\circ} \mathrm{C}$, all medium to high current densities at $30^{\circ} \mathrm{C}$ and no such overshooting at $70^{\circ} \mathrm{C}$. The $70^{\circ} \mathrm{C}$ experiment is the actual behavior one expects from the concentration gradient built-up of anions and cations in liquid electrolytes. To analyze the data, two different overpotentials have been used being the initial overpotential right at the beginning which is either the initial maximum as shown at $-10^{\circ} \mathrm{C}$ or the data point near $0.005 \mathrm{mAcm}^{-2}$ at $70^{\circ} \mathrm{C}$ to account for the double layer formation and other processes with small time constants. The second evaluated overpotential is the one at steady state being usually at the end of the short cycling experiment at $0.07 \mathrm{mAcm}^{-2}$
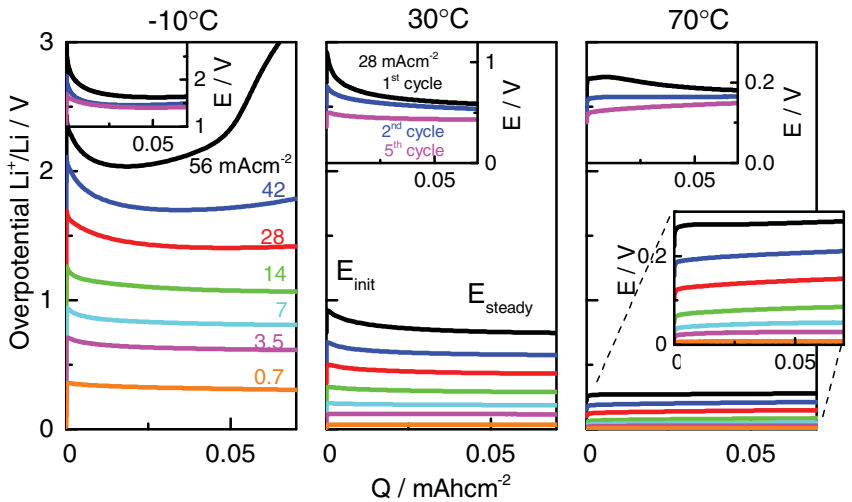

Figure 1. Representative example of dependence of galvanostatic overpotentials on temperature and current density: for symmetric cells of $\mathrm{Li} \mathrm{vs}$. $\mathrm{Li}$ in 1 $\mathrm{M} \mathrm{LiPF}_{6} \mathrm{EC}: \mathrm{DMC} 1: 1 \mathrm{wt}$ for $-10,30$ and $70^{\circ} \mathrm{C}$, same scale applied to show significant temperature-dependence; insets show first two activation cycles before cycling experiments performed; two different overpotentials used for evaluation: initial potential and the steady-state potential usually at the end of the short cycling experiment.

or at the minimum of the total overpotential if electrolyte depletion occurs.

While the initial overpotential represents a nominally unaltered static SEI layer on both electrodes, the steady state overpotential is believed to represent the SEI during continuous reforming. So the initial overpotential represents an upper bound for the estimated parameters while the steady state overpotential represents a lower bound because the SEI might be thinner.

These overpotentials are extracted for sixteen different electrolyte systems of the four different alkali metals in the range from -40 to $+80^{\circ} \mathrm{C}$. Figure 2 depicts the three cases of $\mathrm{Li} / \mathrm{Na} / \mathrm{K}-\mathrm{PF}_{6}$ in EC:DMC 1:1 as representatives. The initial overpotentials from Figure 1 have been plotted as markers with the fit shown as a line. The individual contributions are also depicted from the fit to the Butler-Volmer equation, Ohm's law and Hess equation. Usually the overpotential of each individual process decreases with increasing temperature as expected from Arrhenius type of processes. However, at high temperatures of $>70^{\circ} \mathrm{C}$ for $\mathrm{Li},>50^{\circ} \mathrm{C}$ for $\mathrm{Na}$ and $>30^{\circ} \mathrm{C}$ for $\mathrm{K}$, the ohmic overpotential in the electrolyte increases again with temperature which will be discussed further in Part II of this series. However, of outmost interest is the collapse of the Hessian overpotentials of Li-metal above $10^{\circ} \mathrm{C}$ (greenish blue) and for Na-metal above $60^{\circ} \mathrm{C}$ (red) to negligible small overpotentials. In contrast from -20 to $0^{\circ} \mathrm{C}$ for $\mathrm{Li},-30^{\circ} \mathrm{C}$ to $50^{\circ} \mathrm{C}$ for $\mathrm{Na}$, and at all measured temperatures of -10 to $50^{\circ} \mathrm{C}$ for $\mathrm{K}$, the overpotential according to Hess in Eq. 3 contributes significantly to the total overpotential of these symmetric cells. All sixteen different electrolyte systems are shown in Suppl. Figure S1-S4 for Li, Na, K, and $\mathrm{Rb}$, respectively. It has to be mentioned that the overpotentials based on Eq. 3 for $\mathrm{K}$ is already $300-800 \mathrm{mV}$ per electrode and in the case of $0.05 \mathrm{M} \mathrm{RbClO} 4$ in PC, this overpotential increases to 1-4 $\mathrm{V}$ per Rb-metal electrode. These overpotentials exclude both alkalimetals from real applications besides their significant safety issues as only very little current density can be applied on $\mathrm{Rb}$ electrodes until the cutoff potential of $4.5 \mathrm{~V}$ is reached.

For comparison, also EIS has been applied from $-40^{\circ} \mathrm{C}$ for $\mathrm{PC}$ based electrolytes or down to the crystallization temperature for EC:DMC electrolytes up to $25^{\circ} \mathrm{C}$. These standard Nyquist plots and $\log -\log$ plots are shown in Figure 3. It is important to note that the ohmic resistance from electrolyte increases by one order of magnitude while the SEI resistance changes between two to four orders of magnitude with temperature.

Evaluation of the first semi-circle was performed based on an equivalent circuits of either $R_{1}+R_{2} \| Q_{2}$ or $R_{1}+Q_{2} \|\left(R_{2}+R_{3} \| Q_{3}\right)$ where $R$ and $Q$ represent ohmic resistances and constant phase elements. Usually the most simple circuit is used; however, sometimes a small 
Exp. vs. Fit
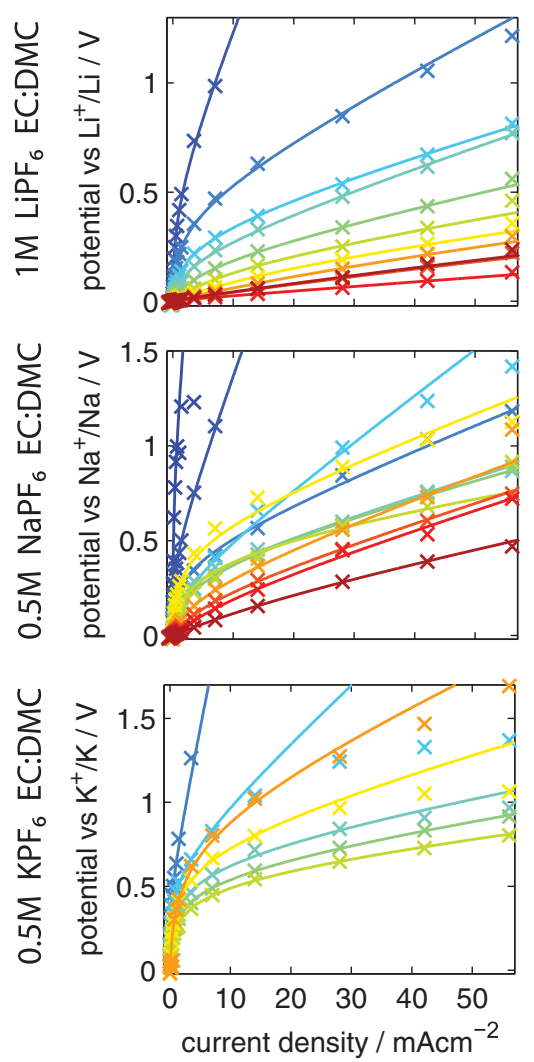

Butler-Volmer
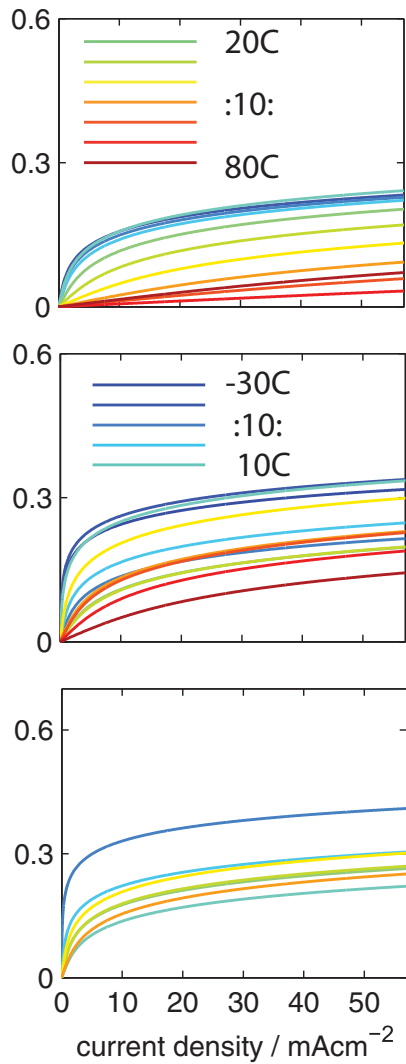

Ohmic contribution
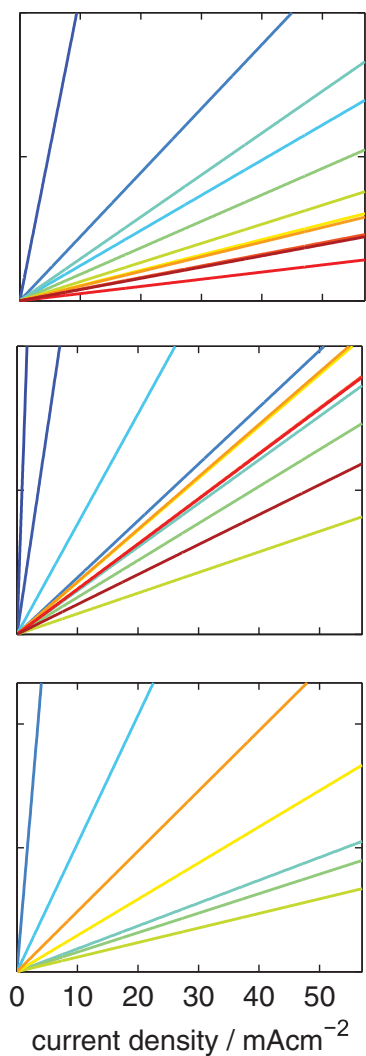

Hessian overpotential
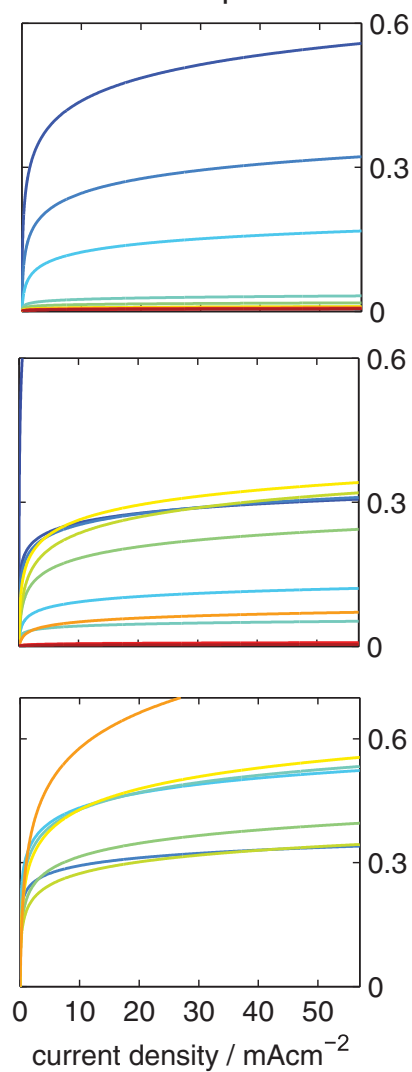

Figure 2. Evolution and fitting of initial overpotentials and single contributions for alkali-metal electrodes with temperature: for the three different examples of $\mathrm{Li} / \mathrm{Na} / \mathrm{K}-\mathrm{PF}_{6}$ in EC:DMC 1:1wt soaked in a Whatman glassfiber separator ranging from -20 to $80^{\circ} \mathrm{C}$ for $1 \mathrm{M} \mathrm{LiPF}_{6},-30$ to $80^{\circ} \mathrm{C}$ for $0.5 \mathrm{M} \mathrm{NaPF}_{6},-10$ to $50^{\circ} \mathrm{C}$ for $0.5 \mathrm{M} \mathrm{KPF}_{6}$; while Li-metal tests work well, $\mathrm{Na}$ and $\mathrm{K}$-metal are less good in their trends and the ohmic resistance increases at high temperatures against the Arrhenius trend; in general) overpotentials increase from $\mathrm{Li}$ over $\mathrm{Na}$ to $\mathrm{K}$ for each specific temperature where the contribution from charge transfer are in the same range for the three alkali metals except that $1 \mathrm{M} \mathrm{LiPF}_{6}$ has slightly higher exchange current densities than its $0.5 \mathrm{M} \mathrm{Na}$ and $\mathrm{K}$ counterparts; the ohmic potential drop is higher for $0.5 \mathrm{M}$ electrolytes as expected, however, the main difference comes from the SEI contribution which is negligible for Li in the range of $10-80^{\circ} \mathrm{C}$ and $\mathrm{Na}$ from $60-80^{\circ} \mathrm{C}$ but very dominant for $\mathrm{Li}$ below $0^{\circ} \mathrm{C}$, Na below $50^{\circ} \mathrm{C}$ and for $\mathrm{K}$ at all measured temperatures.
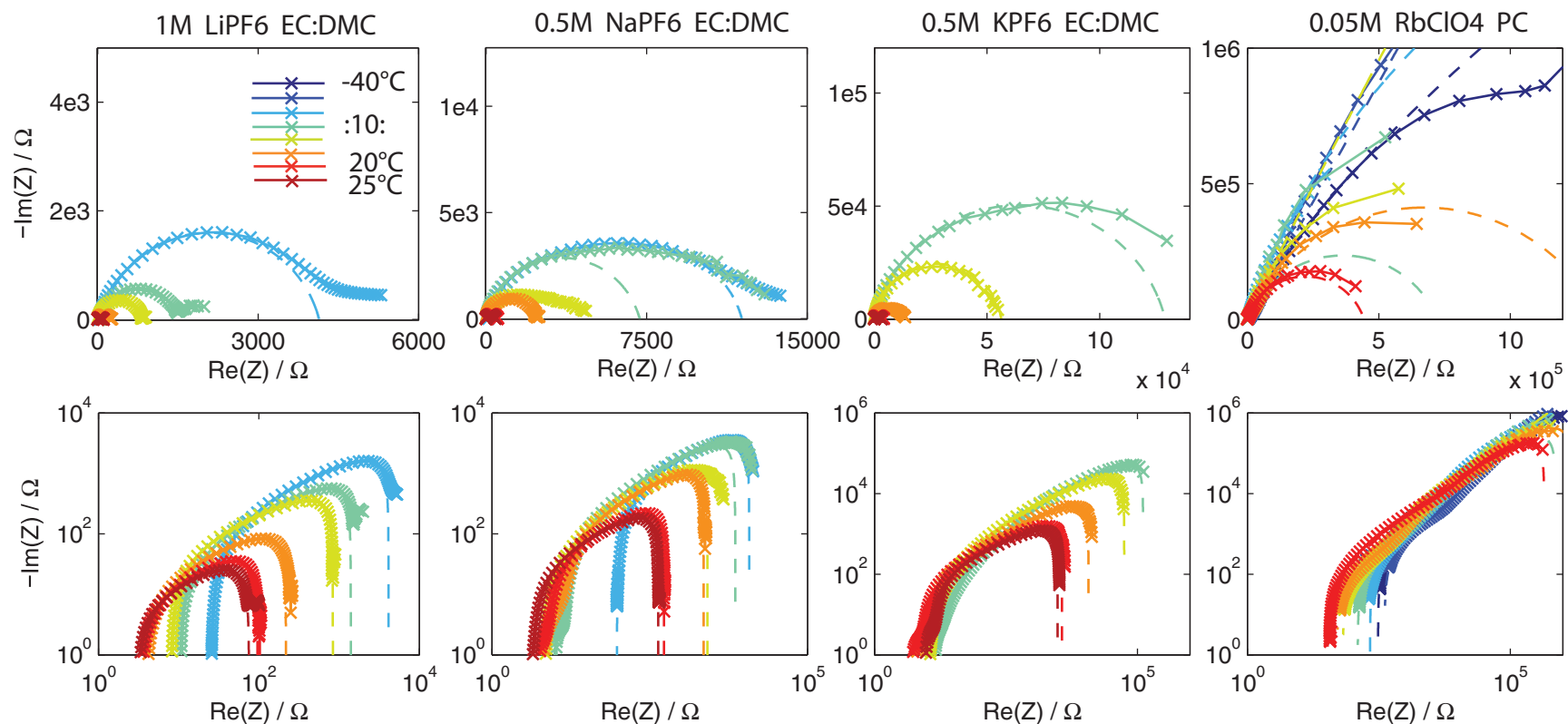

Figure 3. Evolution of electrochemical impedance spectroscopy for alkali-metal electrodes with temperature: for four different samples of $\mathrm{Li} / \mathrm{Na} / \mathrm{K}-\mathrm{PF} 6$ in EC:DMC 1:1wt and $\mathrm{RbClO}_{4}$ in $\mathrm{PC}$ soaked in a Whatman glassfiber separator ranging from -20 to $25^{\circ} \mathrm{C}$ for $1 \mathrm{M} \mathrm{LiPF}_{6}$ and $0.5 \mathrm{M} \mathrm{NaPF}_{6},-10$ to $25^{\circ} \mathrm{C}$ for 0.5 $\mathrm{M} \mathrm{KPF}_{6}$, and -40 to $25^{\circ} \mathrm{C}$ for $0.05 \mathrm{M} \mathrm{RbClO} 4$ in PC; $1^{\text {st }}$ row) standard Nyquist plots showing semi-circle evolution, $2^{\text {nd }}$ row) log-log plot to illustrate significant resistance increases over orders of magnitude with decreasing temperature; markers show experimental data at $10 \mathrm{mV}$ excitation from $500 \mathrm{kHz}$ to $0.01 \mathrm{~Hz}$ and dashed line represents fit with equivalent circuits. 
$\mathrm{Li}$ in $\mathrm{EC}: \mathrm{DMC}$

1M LiPF6, 1M LiClO4, $1 \mathrm{M}$ LiTFSI
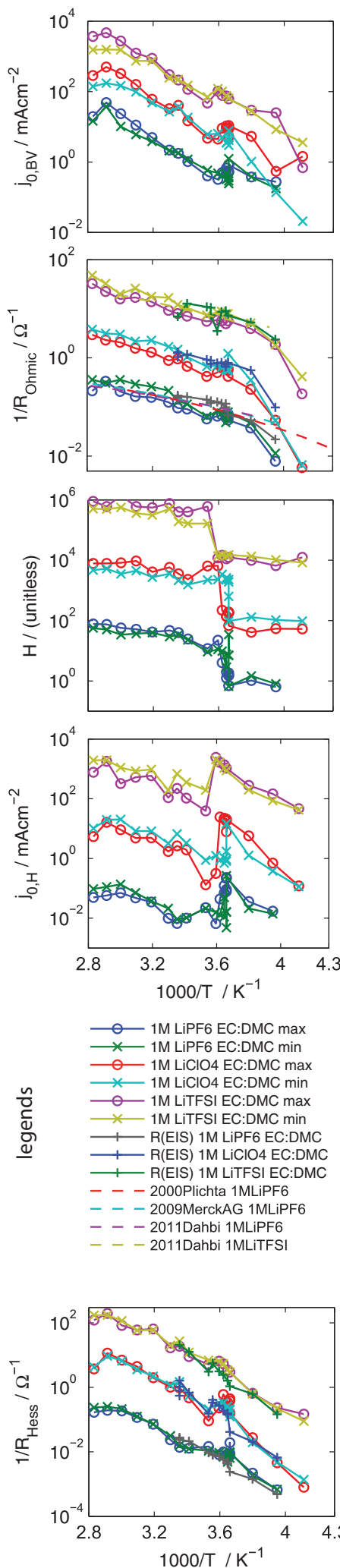

$\mathrm{Li}$ in PC

1M LiPF6, 1M LiClO4, $1 \mathrm{M}$ LiTFSI, $1 \mathrm{M}$ LiBOB
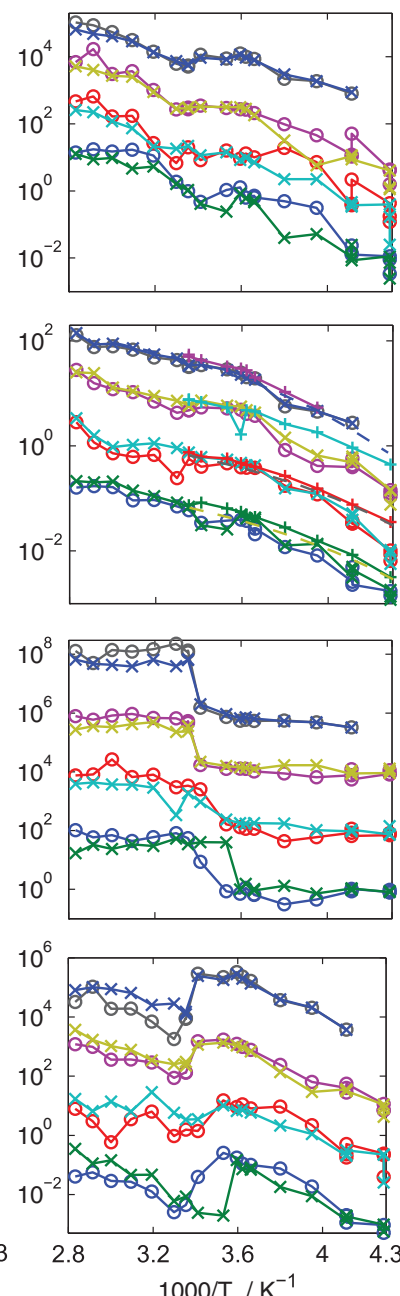

$1000 / \mathrm{T} / \mathrm{K}^{-1}$

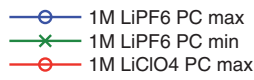

$\simeq \quad 1 \mathrm{M} \mathrm{LiClO} 4 \mathrm{PC}$ min

-1 - $1 M$ LITFSI PC max

$\simeq$ 1M LiTFSI PC min

- 1 - 1 L LIBOB PC max

$\simeq$ 1M LiBOB PC min

। R(EIS) $1 M$ LiPF6 PC

$\longrightarrow$ R(EIS) 1M LiCIO4 PC

— R(EIS) 1M LiTFSI PC

$\longrightarrow$ R(EIS) $1 M$ LIBOB PC

- - 1979Bathel 1.07MLPFo

- - - 1979Barthel 0.94ML

_ - - 2005DingXu 0.97MLiBOB

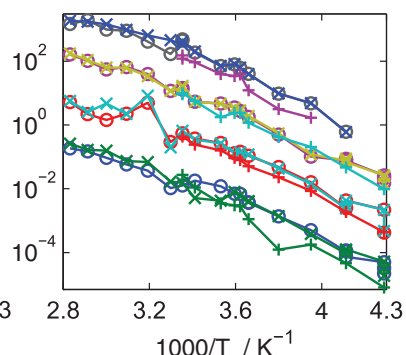

$\mathrm{Na}$ in

0..5M/1M NaPF6 EC:DMC/PC $1 \mathrm{M} \mathrm{NaClO} 4 \mathrm{EC}: \mathrm{DMC} / \mathrm{PC}$
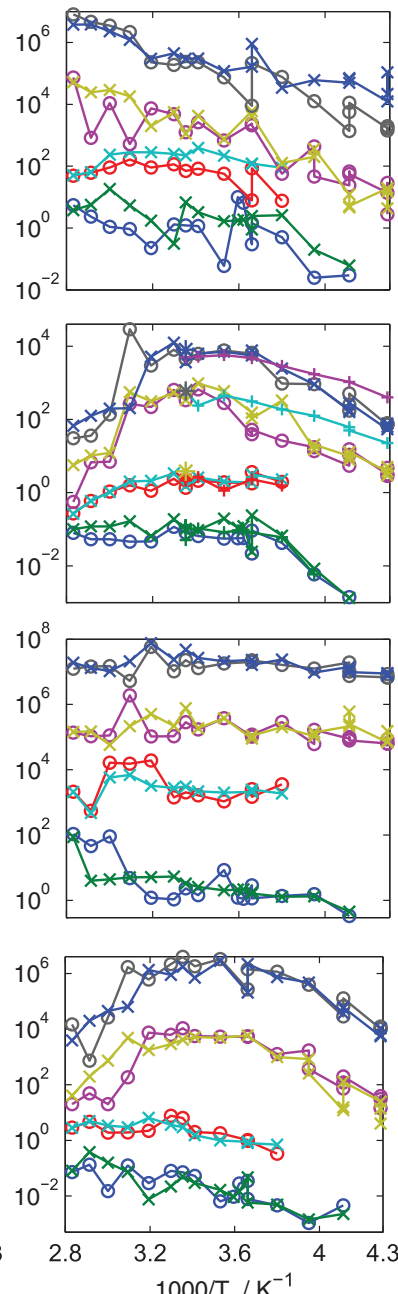

- $0.5 \mathrm{M}$ NaPF6 EC:DMC max $\longrightarrow 0.5 \mathrm{M} \mathrm{NaPF6}$ EC:DMC min - $1 \mathrm{M} \mathrm{NaClO4}$ EC:DMC max $\times$ 1M NaClO4 EC:DMC min - $1 \mathrm{M}$ NaPF6 PC max $\longrightarrow$ 1M NaPF6 PC min - $1 \mathrm{M} \mathrm{NaClO} 4 \mathrm{PC}$ max $\leftarrow$ 1M NaClO4 PC min $\longrightarrow$ R(EIS) 0.5M NaPF6 EC:DMC —— R(EIS) $1 \mathrm{M} \mathrm{NaClO} 4 \mathrm{EC}: \mathrm{DMC}$ — R(EIS) 1M NaPF6 PC - $\mathrm{R}(\mathrm{EIS}) 1 \mathrm{M} \mathrm{NaClO} 4 \mathrm{PC}$

* 2012Pon $1 \mathrm{MNaClO} 4 \mathrm{ECDMC}$

2012P $1 \mathrm{MN} 1 \mathrm{MN}$ ECOMPC

* 2012Ponrouch

* 2012Ponrouch 1MNaClO4 PC

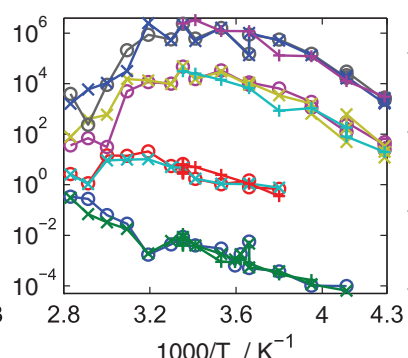

$\mathrm{K}$ or $\mathrm{Rb}$ in

$0 . .5 \mathrm{M} / 1 \mathrm{M}$ KPF6 EC:DMC/PC 0.05M K/RbClO4 EC:DMC/PC
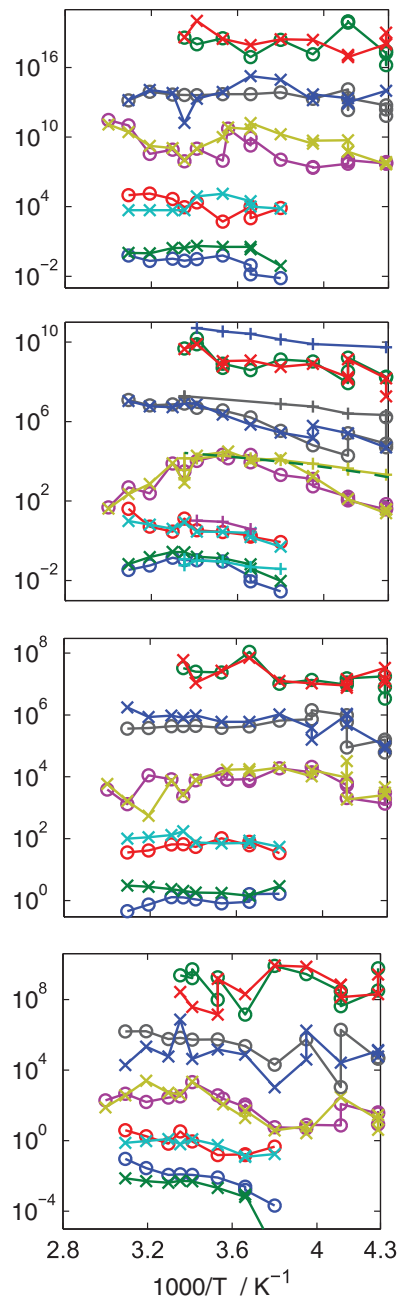

$1000 / \mathrm{T} / \mathrm{K}^{-1}$

- $0.5 \mathrm{M} \mathrm{KPF6}$ EC:DMC max

× 0.5M KPF6 EC:DMC min

- $0.05 \mathrm{M} \mathrm{KCIO} 4 \mathrm{EC}: \mathrm{DMC}$ max

$\longrightarrow 0.05 \mathrm{M} \mathrm{KClO} 4 \mathrm{EC}: \mathrm{DMC}$ min

- $1 \mathrm{M} \mathrm{KPF6} \mathrm{PC} \mathrm{max}$

$-0.05 \mathrm{M} \mathrm{KClO} 4 \mathrm{PC}$ max

$+\quad 0.05 \mathrm{MKCIO4} P \mathrm{PC}$ max

- $0.05 \mathrm{MClO4PC}$ min

$+0.05 \mathrm{RbClO} P \mathrm{PC}$ max

$\longrightarrow 0.05 \mathrm{M} \mathrm{RbClO} 4 \mathrm{PC}$ min

1 $\mathrm{R}$ (EIS) 0.5M KPF6 EC:DMC

—— R(EIS) 0.05M KClO4 EC:DMC

- R(EIS) $1 \mathrm{M} \mathrm{KPF6} \mathrm{PC}$

$1-\mathrm{R}$ (EIS) $0.05 \mathrm{M} \mathrm{KClO} 4 \mathrm{PC}$

— R(EIS) 0.05M RbClO4 PC

_ - - 1979Barthel 0.92M KPF6 PC

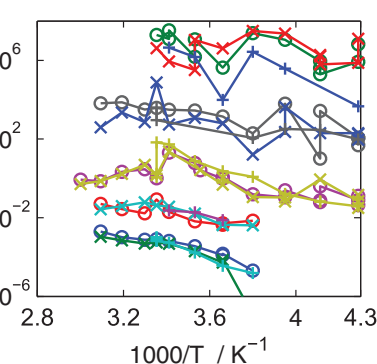

Figure 4. Parameter set of best fit of symmetrical $\mathrm{Li}, \mathrm{Na}, \mathrm{K}$ and $\mathrm{Rb}$ cells with three processes Butler-Volmer, Ohm and Hess: for sixteen different systems of column: 1) Li in EC:DMC 2) Li in PC, 3) Na and 4) $\mathrm{K}$ and $\mathrm{Rb}$ with row 1) exchange current density $j_{0, B V}, 2$ ) ohmic conductance of GS and EIS experiments, 3) muting factor $H$, 4) exchange current density $j_{0, H}$ which are all four independent variables while row 6) plots the derived Hessian resistance combining $H$ and $i_{0, H}$ in Eq. 6 showing the match with the SEI resistance from EIS experiments; electrolyte conductivity data ${ }^{25-30}$ has been added in row 2 ) to show the match. 
pre-circle at high frequency needs to be included to fit the standard high-resistance semi-circle. No data at low frequency was evaluated as unphysical high surface areas and small exponents of the constant phase element of values between 0.5 and 0.7 indicate severe issues with either the data or the assumptions of using $R Q$ elements as discussed in Ref. 1. Thus, only the electrolyte resistance and the first semi-circle in EIS have been used in this study.

The fit with equivalent circuits is shown as dashed lines in Figure 3. The observed resistances vary between circa $40 \Omega$ for the case of 1 $\mathrm{M} \mathrm{LiPF}_{6} \mathrm{EC}: \mathrm{DMC}$ at $25^{\circ} \mathrm{C}$ up to $2.2 \cdot 10^{8} \Omega$ for $0.05 \mathrm{M} \mathrm{RbClO}_{4}$ in $\mathrm{PC}$ at $-40^{\circ} \mathrm{C}$ for a geometric electrode area of $1.33 \mathrm{~cm}^{2}$. The lowest resistances of the first semi-circle are found for $1 \mathrm{M} \mathrm{LiClO}_{4}$ and $1 \mathrm{M}$ LiTFSI in EC:DMC with circa $19 \Omega$ at $25^{\circ} \mathrm{C}$ which is in line with literature ${ }^{24}$ and shown in Suppl. Fig. S5, S6. While the SEI resistances for $\mathrm{Li}$ electrolytes are still in a range where operation might be possible, the $220 \mathrm{M} \Omega$ for $\mathrm{Rb}$ would simply represent a heat source if this resistance would be linear throughout the different current densities.

Extracted parameters of transport processes.-Figure 4 shows the parameter trends of the exchange current density of Butler-Volmer $j_{O, B V}$ and Hess $j_{0, H}$, the inverse ohmic resistance reflecting the conductivity $1 / R_{O h m}$ and the muting factor $H$ as a function of $1 / T$ in Arrhenius plots. While these four parameters are individual variables, the derived value of the Hessian resistance in Eq. 6 is displayed in the last row of Figure 4. Additionally, the electrolyte resistance from EIS corrected for the transference number $t_{L i}=0.56^{22}$ and SEI resistance extracted from the fit to the first semi-circle in the EIS experiment have been plotted in the $1 / R_{\text {Ohm }}$ and $1 / R_{\text {Hess }}$ plots showing the match for all four alkali-metal electrodes.

The lines in Figure 4 have been arbitrarily shifted to show similarities and respective trends. Each electrolyte system is plotted individually in Suppl. Figure S7-S10 for better visibility. The initial overpotential for each electrolyte, current density and temperature is displayed with circles while the steady state overpotential has x markers reflecting both the maximum and minimum parameter estimate from galvanostatic cycling. The different systems have been sorted for similar behavior as $\mathrm{Li}$ salts in $\mathrm{EC}: \mathrm{DMC}, \mathrm{Li}$ salts in $\mathrm{PC}, \mathrm{Na}$ salts and last $\mathrm{K} / \mathrm{Rb}$ salts.

While the exchange current density $j_{0, B V}$ shows small fluctuations and typical Arrhenius type of behavior for $\mathrm{Li}$, this exchange current density has enormous errors up to two orders of magnitude in the case of $\mathrm{Na}, \mathrm{K}$ and $\mathrm{Rb}$ metal due to increasing reactivity in the order of $\mathrm{Na}, \mathrm{K}, \mathrm{Rb}$. In contrast, the ohmic resistance shows small errors and continuous trends. For several electrolyte systems, the measured conductivity for the pure electrolyte could be added in the $1 / R_{O h m}$ plots when adapted for the properties of the glassfiber separator and transference number. This was the case for $\mathrm{LiPF}_{6}$ and LiTFSI in EC:DMC ${ }^{25-27} \mathrm{LiPF}_{6}, \mathrm{LiClO}_{4}$ and $\mathrm{KPF}_{6}$ in $\mathrm{PC} ;{ }^{.8} \mathrm{LiBOB}^{2} \mathrm{PC}^{29}$ and the conductivity of three $\mathrm{Na}$ systems but at $25^{\circ} \mathrm{C}$ only. ${ }^{30}$ These eight electrolyte conductivities match the extracted ohmic resistance. Only, the electrolyte resistance from EIS adapted already by the transference number is in all cases smaller than the one determined from galvanostatic experiments, however, only within a certain error. In general, the electrolyte resistance is the only parameter here, which can be compared to literature values as very precise conductivity meters exist and the conductivities have been tabulated. ${ }^{25-29}$

However, the main feature is the muting factor $H$ and the exchange current density $j_{O, H}$ of the SEI resistance. For all seven Li systems a jump of both $H$ and $j_{0, H}$ is observed with a change of each parameter of one to two orders of magnitude. This jump is sudden and seems to be similar to a phase transition. The critical temperatures are individual for each electrolyte system and seem to be independent from the crystallization temperature of e.g. a $1 \mathrm{M}$ salt in the EC:DMC phase diagram. ${ }^{31}$ They are also observed for all four PC-based Li electrolytes. Furthermore, this sudden jump is detected for $0.5 \mathrm{M} \mathrm{NaPF}_{6}$ in EC:DMC; however, at much higher $T_{C}$ between $50-60^{\circ} \mathrm{C}$. No such phase transition is observed for neither of the other three Na systems nor $\mathrm{K}$ or Rb. While $j_{0, B V}, 1 / R_{O h m}$ and $j_{0, H}$ show typical Arrhenius type
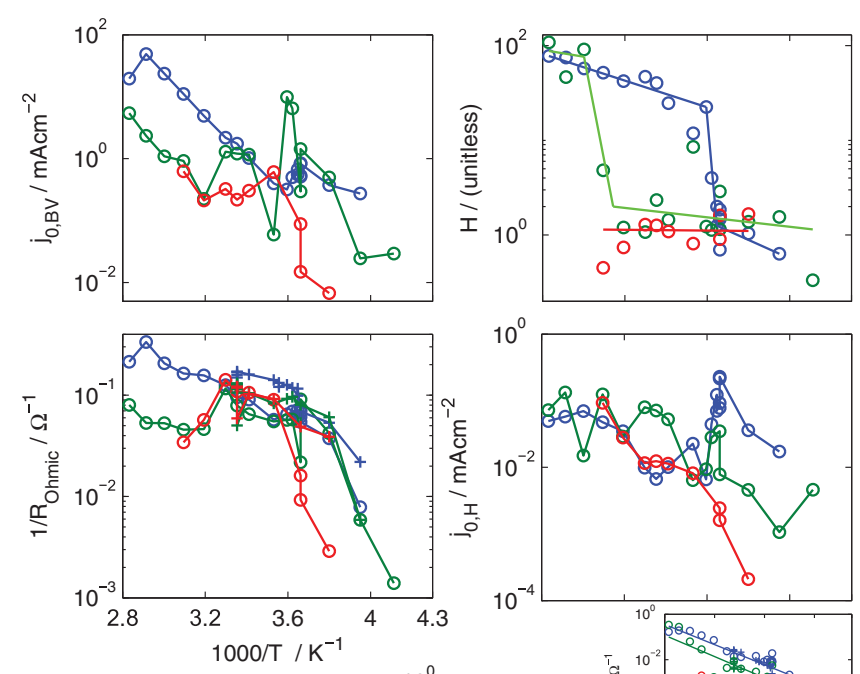

$10^{-4}$

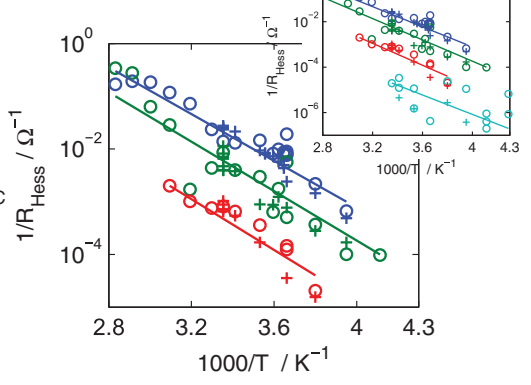

Figure 5. Comparison of alkali- $\mathrm{PF}_{6} \mathrm{EC}: \mathrm{DMC}$ : plots of $j_{0, B V}, 1 / R_{O h m}, H$ and $i_{0, H}$ vs. $T^{-1}$ show an order of magnitude higher exchange current and ohmic resistance for $1 \mathrm{M} \mathrm{LiPF}_{6}$ compared to $0.5 \mathrm{M} \mathrm{Na} / \mathrm{KPF}_{6}$; in contrast $H$ seems to be relatively similar for all three electrolytes below $T_{C}$; however, both $\mathrm{Li}$ and $\mathrm{Na}$ indicate a phase transition toward high $H$ meaning small SEI overpotentials; also $i_{0, H}$ seems to be rather similar for the three electrolytes within a very high error bar shown from the fluctuation; merging of $H$ and $i_{0, H}$ gives the resistance $R_{\text {Hess }}$ which fits for all four alkali metals over seven orders of magnitude to the resistance of the first semi-circle of the EIS experiments.

of behavior, the muting factor $H$ seems to be rather independent of temperature, except at the phase transition near $T_{C}$.

The data here shows a dilemma for industrial applications. Usually one adds PC to EC:co-solvent mixtures to decrease the crystallization temperature of electrolytes and guarantee a good low temperature operation. However, here all three different $1 \mathrm{M}$ salts of $\mathrm{LiPF}_{6}, \mathrm{LiClO}_{4}$ and LiTFSI have circa $10-15^{\circ} \mathrm{C}$ higher $T_{C}$ of the SEI resistance in pure PC than in their EC:DMC counter parts. Thus, while one improves ionic conductivity in the electrolyte, one might decrease ionic conductivity in the SEI. The behavior for ternary solvent system is missing here; however, this important aspect should be mentioned at least.

Comparison of alkali-metal parameters.-Figure 5 shows the Arrhenius plots of Figure 4 for the cases of $1 \mathrm{M} \mathrm{Li}-, 0.5 \mathrm{M} \mathrm{Na}$ - and 0.5 $\mathrm{M} \mathrm{KPF}_{6}$ in EC:DMC 1:1. While the error bar is significant for $\mathrm{Na}$ and $\mathrm{K}$, trends can still be extracted as the parameters change over orders of magnitude themselves. While the exchange current density $j_{O, B V}$ and $1 / R_{O h m}$ are smaller for the $0.5 \mathrm{M} \mathrm{Na}$ and $\mathrm{K}$ electrolytes, as expected, the main difference can be seen in the $H$ parameter which has a sudden jump at certain $T_{C}$ for both $\mathrm{Li}$ and $\mathrm{Na}$, however, circa $50^{\circ} \mathrm{C}$ apart. It is important to note that the $H$ parameter is very similar for $T<T_{C}$ for $\mathrm{Li} / \mathrm{Na}$ and for $\mathrm{K}$ at all temperatures. Also above $T_{C}, \mathrm{Li}$ and $\mathrm{Na}$ seem to have a similar $H$ parameter. Thus, there might be a common transport phenomenon associated with these alkali metals for a certain temperature range. Also $j_{0, H}$ is similar for these different alkali metals except at low temperature below circa $5^{\circ} \mathrm{C}$.

The derived Hessian resistance calculated from $j_{0, H}$ and $H$ in Eq. 6 is plotted in the lowest subfigure of Figure 5. One can clearly observe 


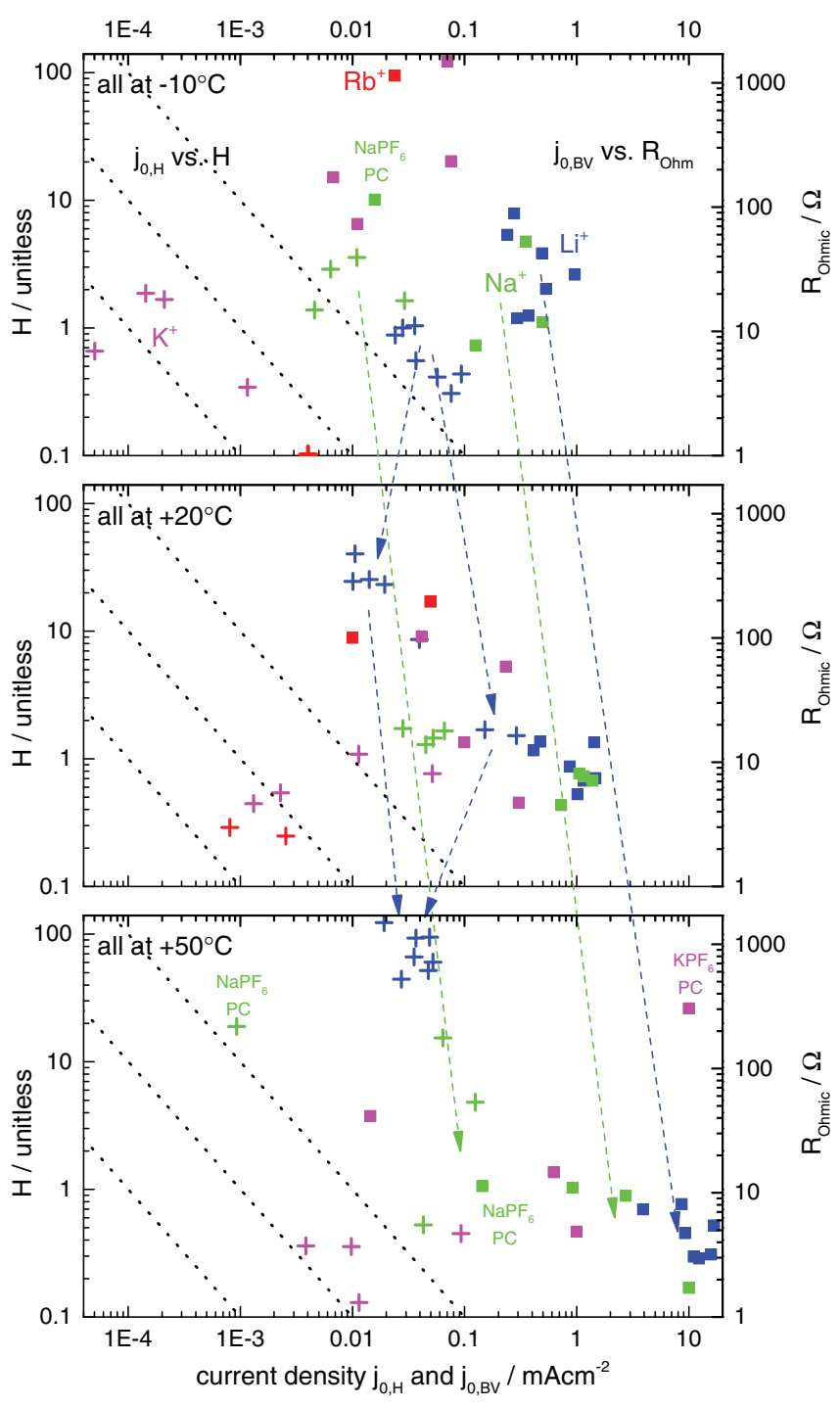

Figure 6. Parameter clustering and evolution for the three processes: plots at $-10,+20$ and $+50^{\circ} \mathrm{C}$ for all sixteen measured electrolyte systems for $\mathrm{Li}$ (blue), $\mathrm{Na}$ (green), $\mathrm{K}$ (magenta) and $\mathrm{Rb}$ (red) with markers for $j_{0, H}$ vs $H$ (plus) and $j_{O, B V}$ vs. $R_{O h m}$ (square); black dotted lines reflect equi-resistance lines for $R_{\text {Hess }}$ which is usually measured by EIS, dashed blue and green arrows indicate parameter evolution where the two Li electrolytes LiTFSI and LiBOB in PC have their critical temperature $T_{C}$ between $20-25^{\circ} \mathrm{C}$ so splitting of parameter cluster at $20^{\circ} \mathrm{C}$, no arrows for $\mathrm{K}$ and $\mathrm{Rb}$ due to very different salt molarity.

straight lines for $\mathrm{Li}, \mathrm{Na}, \mathrm{K}$ and also $\mathrm{Rb}$ in the inset. Despite $H$ and $j_{0, H}$ jumping over two orders of magnitude at $T_{C}$, they compensate each other and will be invisible during EIS experiments. And indeed, in the last row of Figure 4, both the Hessian resistance calculated from Eq. 6 and the SEI resistance determined from EIS in Figure 3 match and only straight lines with small fluctuations in the regime near $T_{C}$ can be observed.

To show the similarity of the four fitting parameters for the three overpotentials, the parameters have been plotted in Figure 6 for -10 , +20 and $+50^{\circ} \mathrm{C}$ to maximize the amount of data points. On the left, $H$ is plotted vs. $j_{O, H}$ with equi-resistance lines added to show similar resistance lines from Eq. 6 . On the right axis, $R_{O h m}$ is plotted vs. $j_{O, B V}$ which do not have a physical dependence or correlation. One can observe that the charge transfer reaction is very similar for all seven Li electrolyte systems and three out of four Na systems. This is consistent throughout the different temperatures. $\mathrm{K}$ and $\mathrm{Rb}$ are not compared as they have very different molarity ranging from $0.05 \mathrm{M}$ to $1 \mathrm{M}$ and enormous error bars due to their high reactivity and dendrite growth rate. These error bars are shown in Suppl. Figure S11 for each individual alkali-metal parameter at the three temperatures. Based on these error bars, one can confirm that $j_{O, B V}$ has the lowest sensitivity in GS experiments due to very high exchange current density for metals in general and therefore non-limiting character. In contrast, $j_{0, H}$ and $H$ have relative small error bars and are usually the most sensitive during GS and EIS measurements, while $1 / R_{O h m}$ has intermediate error bars. In general, the error bars increase from $\mathrm{Li}$ over $\mathrm{Na}$ and $\mathrm{K}$ to $\mathrm{Rb}$ due to higher reactivity and dendrite growth rate. However, also the low solubility of $\mathrm{K}$ and $\mathrm{Rb}$ salts in carbonates increases the uncertainty due to less good electrolyte conduction and charge transfer.

A second comparison in Figure 6 shows that also the $H$ and $j_{0, H}$ parameters cluster for both $\mathrm{Li}$ and $\mathrm{Na}$ at each temperature. At $20^{\circ} \mathrm{C}$ one can observe a splitting of the seven different electrolytes of $\mathrm{Li}$ because $1 \mathrm{M}$ LiTFSI and $1 \mathrm{M} \mathrm{LiBOB}$ in PC have their $T_{C}$ between $20-25^{\circ} \mathrm{C}$ while the other five $\mathrm{Li}$ electrolytes have their $T_{C}$ between $0-20^{\circ} \mathrm{C}$. However, at $50^{\circ} \mathrm{C}$ all Li-based electrolytes cluster again as all are well above $T_{C}$. Exception from this general clustering is detected for $\mathrm{PF}_{6}{ }^{-}$in $\mathrm{PC}$ and $\mathrm{Na}$ electrolytes at higher temperature which will be discussed in Part II of this series.

The exchange current $j_{0, B V}$ is very similar for all seven $\mathrm{Li}$ and three different Na electrolytes as shown in Figure 6, and also the fitted ohmic resistance matches literature in Figure 4 for all found electrolyte conductivities in literature. Thus, one can be relatively certain that the usage of these three equations unifies our understanding of alkaliion batteries. The parameters converge for EIS and GS over seven orders of magnitude for the SEI resistance. Also, charge transfer of the electron hoping from the metal electrode to the alkali-ion is very similar for the same alkali-metal with a weak dependence on salt and solvent, however, a significant dependence on concentration and temperature.

\section{Discussion}

Behavior near critical temperature.-The serendipity of finding a critical temperature for all seven tested Li-based electrolytes and one $\mathrm{Na}$ electrolyte is very difficult if not impossible to observe directly from the overpotential profiles. The temperature profiles of $-10,30$ and $70^{\circ} \mathrm{C}$ of Figure 1 show basically no obvious anomaly at $0^{\circ} \mathrm{C}$ and $5^{\circ} \mathrm{C}$ which are just below and above the critical temperature $T_{C}$ (SI Fig. S12).

Figure 7 shows the evolution of the parameters of $\mathrm{Li} / \mathrm{Na}-\mathrm{PF}_{6}$ in EC:DMC near their individual $T_{C}$. A zoom to only $0-1.5 \mathrm{mAcm}^{-2}$ has been chosen to improve visibility. At temperatures above $T_{C}$, the overpotential from the SEI is negligible. Between $0-5^{\circ} \mathrm{C}$, and $50-60^{\circ} \mathrm{C}$ a sudden change of the overall contribution can be observed for $1 \mathrm{M} \mathrm{LiPF}_{6}$ and $0.5 \mathrm{M} \mathrm{NaPF}_{6}$ in $\mathrm{EC}: \mathrm{DMC}$, respectively. A precise $T_{C}$ cannot be given, first, because the temperature intervals are too broad being usually $10^{\circ} \mathrm{C}$. Second, and even more important, $T_{C}$ is different for the initial and steady-state overpotential evaluation by a few degree as shown in Figure 4. For the case with the best temperature resolution of $1 \mathrm{M} \mathrm{LiPF}_{6}$ and $1 \mathrm{M} \mathrm{LiClO}_{4}$ both in EC:DMC, $T_{C}$ of the steady state overpotential is in the range of 1 to $4^{\circ} \mathrm{C}$ lower than the one determined from the initial overpotential. Thus, either there is fitting uncertainty or ionic conduction in the inner SEI is worse for thick stable SEIs after a 10 min open-circuit relaxation than for continuous built-up of new thin SEI layers on the freshly deposited alkali metal during galvanostatic cycling. Both possibilities are reasonable.

The charge transfer reaction often compensates for the rapid changes of the SEI transport near $T_{C}$ which can be seen by jumps of $j_{O, B V}$ in most of the seven Li-based electrolytes. However, far below $T_{C}$, Butler-Volmer cannot compensate anymore for the rapidly increasing experimental overpotential. One needs to stress that uncertainty for the very small overpotential contribution in the case of $\mathrm{Li}$ could have originated easily from fluctuation or systematic errors. But the match of the SEI resistance from EIS with the one from GS for all four alkali metals over orders of magnitude, the higher $T_{C}$ of $\mathrm{Na}$ compared to Li and the overall clustering of parameters in general 
Exp. vs. Fit
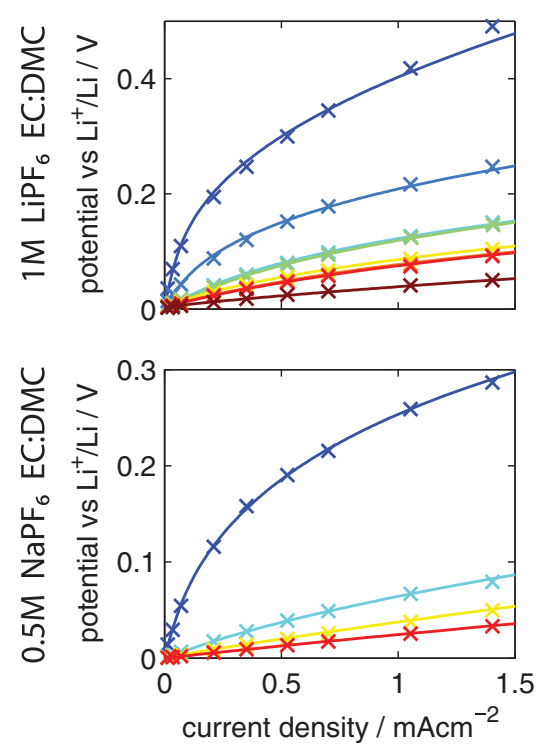

Butler-Volmer
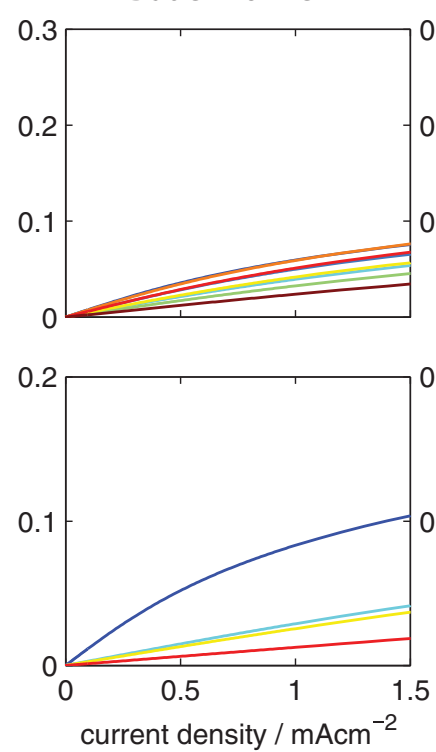

Ohmic contribution
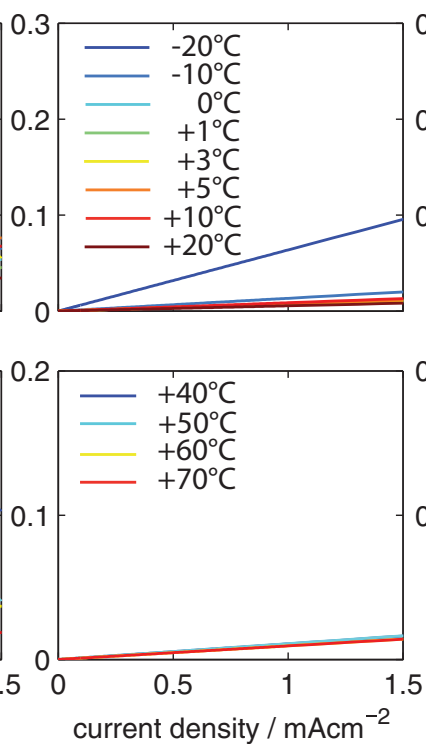

Hessian overpotential
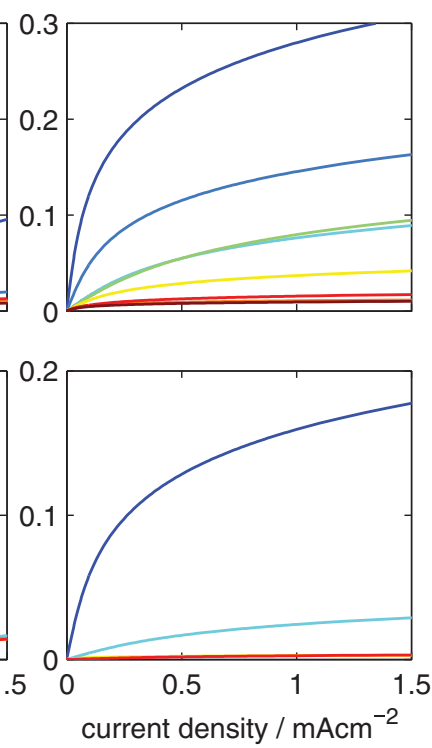

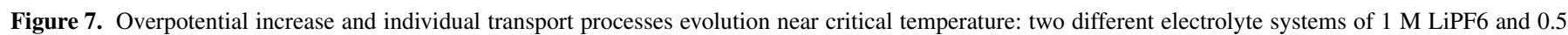

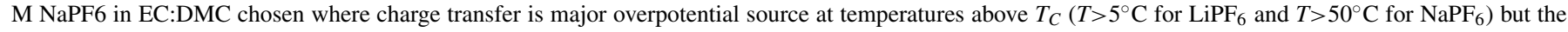

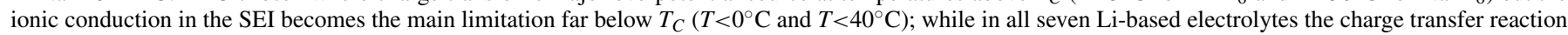

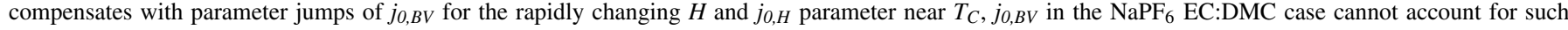
dramatic change of the SEI resistance anymore; however, uncertainty persists due to significant assumptions made to evaluate the data.

for different electrolytes could be an indicator that there might be common transport mechanisms for all alkali-ions.

However, one has to keep in mind that dendrite growth, asymmetries of Butler-Volmer and Hess equation, and changes of the electrodes during cycling cannot be compensated in the symmetric cell setup tested here. Also, if one choses another fitting algorithm with equally weighted current densities (e.g $10 \mathrm{mV}$ difference at 50 and $0.01 \mathrm{~mA}$ weighted equally), one fails to extract consistent parameters for Equation 3 (SI Fig. S14). This is due to the sensitivity of the equation to low and very low current densities only (SI Fig. S15). Thus, further research needs to be conducted to reveal the underlying transport mechanism.

Distinct critical temperature.-The author of this publication is very sceptic with regard to a precise phase transition with a defined critical temperature. The SEI is made out of various deposition products which react non-selectively once the alkali-metal is immersed in an electrolyte. While there seem to be common reduction products in the outer and inner SEI, ${ }^{32}$ their crystallinity, grain boundaries, porosity distribution and polymer chain length should vary widely. Thus, it is very questionable if a distinct phase transition occurs uniformly over the entire area of the SEI.

A rather continuous transition with variations due to impurities, age, concentration differences, and applied current density is more likely to be present. But the two assumptions of just three transport processes being all in series and a perfect symmetry might be too restrict to allow the fitting process a smoother transition. Therefore, the hypothesis of two different transport mechanisms in the SEI in parallel (e.g. bulk and grain boundary ion conduction) and simply two different SEIs on the charged and discharged alkali metal electrode have been tested. And indeed, the addition of a second transport either in series (assumption $i_{B V}=i_{O h m}=i_{H 1}=i_{H 2}$ ) or in parallel to the first Hess equation (assumption $i_{B V}=i_{O h m}=i_{H 1}+i_{H 2}$ ) resulted in a good fit near the critical temperature especially for the parallel model (SI Fig. S16). However, the features of the overpotential to current density profiles (e.g. seen in Fig. 2) are simply too weak to be able to determine six fitting parameters independently. Thus, there remains uncertainty near the critical temperature.
But one aspect is very clear. The overpotential of the SEI changes to highly resistive values at low temperatures. This is validated by GS and EIS, independent of the fitting procedure (SI Note 5) and independent of any assumption made to evaluate its origin. While the muting factor $H$ can already merge the EIS and GS data over seven orders of magnitude, another approach might further simplify the present model. Therefore, other researchers are encouraged to investigate the SEI overpotentials and help to shed some light on this particular issue in battery research.

Mechanisms of ionic conduction.-Assuming that systematic errors do not influence the extracted parameters significantly and that a phase transition with a destinct critical temperatures does exist, one can analyze the underlying ionic transport mechanism. On the one hand, there seems to be a common transport mechanism through the $\mathrm{SEI}$ for $\mathrm{Li}, \mathrm{Na}, \mathrm{K}$ and $\mathrm{Rb}$ below $T_{C}$ which depends mainly on the conducted alkali-ion $\left(1 / R_{\text {Hess }}\right.$ in Figure 5$)$. On the other hand, a sudden jump of the $H$ and $j_{O, H}$ parameter over 1.5 to two orders of magnitude for all seven Li electrolyte systems and one out of four $\mathrm{Na}$ systems shows another contribution. Three possibilities seem to be able to explain this anomaly.

First, a significant asymmetry of the deposition and dissolution reaction both in the Butler-Volmer and Hessian equation together with significant dendrite growth could increase the surface area for $j_{0, B V}$ and $j_{0, H}$. This could lead to two very different morphologies of the alkali electrodes in the symmetric cells. The basic assumption of symmetry would, thus, recognize two different processes artificially. Only a reference electrode or asymmetric cells with e.g. graphite or $\mathrm{TiS}_{2}$ counter electrodes could be able to quantify the asymmetry.

Second, the jump of $H$ and $j_{0, H}$ could be associated with a first order phase transition of one process alone at a critical temperature $T_{C}$. Below $T_{C}$ only slow conduction would be possible while above $T_{C}$ the ions can be transported easily.

The third possibility is based on two different transport mechanisms through the inner dense SEI which are in parallel. One mechanism can conduct alkali ions very well but undergoes a phase transition during some kind of reordering of its underlying atomic configuration or a glass transition at $T_{C}$. The second process conducts ions at all temperatures from -40 to $+80^{\circ} \mathrm{C}$ but with a much higher associated 
overpotential/energy for ion hopping. This could be, e.g., bulk ionic conduction in the grains and in parallel grain boundary conduction where $\mathrm{j}_{0, \mathrm{H}}$ would be much smaller for the better conducting grain boundary conduction which would be in line with the jump too lower $\mathrm{j}_{0, \mathrm{H}}$ values above $\mathrm{T}_{\mathrm{C}}$ in Figure 4 . Thus, with the data presented here, this parallel conduction of alkali-ions in the bulk at all temperatures and along the grain boundaries above $T_{C}$ seems to be the most plausible one.

What is the error if we have two parallel processes but use just one process to fit the data to get Figure 4. Let us consider that at a certain temperature sufficiently far from $T_{C}$, mainly one process dominates due to its significantly smaller ionic resistance. Thus, if both resistances are in parallel and e.g. one process has 10x smaller ionic resistance it carries $91 \%$ of the current. If we have two orders of magnitude difference, as we observe here, the better process carries already $99 \%$ of the current. Thus, sufficiently far from $T_{C}$, the basic assumption $i_{B V}=i_{O h m}=i_{\text {Hess }}$ would hold and the data analysis presented in this paper would have only $1 \%$ error.

The other extreme case considers operation directly at $T_{C}$ where both process have similar resistances. Thus, the total resistance of both processes would be just half of each individual one. However, assuming that a single process carries all current and not just half would result in an underestimation of the resistance by a factor of two. This could explain the underestimation of the Hessian resistance near $T_{C}$ in Figure 4.

Calculations based on two different SEI resistances a) in series and $b$ ) in parallel for the possibilities one and three are simulated in SI Note 6. The transport of ions in two different but parallel ion transport mechanisms fits the experimental data best near the critical temperature. Therefore, it is likely that two different transport mechanisms exist where the more efficiently one shuts down at a certain $T_{C}$ and only the basic transport mechanism is left. While $T_{C}$ could be determined for all $\mathrm{Li}$ electrolytes and one $\mathrm{Na}$ electrolyte, the other three Na-electrolytes and the $\mathrm{K}$ and $\mathrm{Rb}$ cells only show one transport mechanism. However, from the increase of $T_{C}$ from $\mathrm{Li}$ to $\mathrm{Na}$, one would expect $T_{C}$ to be above the melting point of $\mathrm{K}$ and $\mathrm{Rb}$-metal and therefore could not be tested in the current setup. The comparison of the $H$ parameter with the Young equation ${ }^{14,15}$ yields non-physical SEI thicknesses in the range of $\AA$ for both of the two ionic conduction processes. Thus, further research is necessary to detect the origin of the underlying transport mechanisms and their associated SEI overpotentials.

\section{Conclusions}

Investigation of symmetrical electrodes of $\mathrm{Li}, \mathrm{Na}, \mathrm{K}$, and $\mathrm{Rb}$ metal confirms that the overpotential of the solid-electrolyte interphase is strongly non-linear over the temperature range from $-40^{\circ} \mathrm{C}$ up to $80^{\circ} \mathrm{C}$ for carbonate based electrolytes. The empirical equation proposed earlier, ${ }^{1}$ can merge the non-linear SEI resistance from galvanostatic experiments in the range from a few $\mathrm{mV}$ for $\mathrm{Li}$ up to several $\mathrm{V}$ for $\mathrm{Rb}$ to the first semi-circle in the Nyquist plots from electrochemical impedance spectroscopy ranging from circa $26 \Omega \mathrm{cm}^{2}$ for $\mathrm{Li}$ up to $292 \mathrm{M} \Omega \mathrm{cm}^{2}$ for $\mathrm{Rb}$. The match of the ohmic resistance in the electrolyte with literature data of precise determined electrolyte conductivities and the overall similarity of the exchange current densities of Butler-Volmer for the same alkali-metal in various different electrolyte systems seems to confirm that the currently proposed equation for the ionic transport within the inner SEI might unify the understanding of alkali-metal electrodes.

Also indicators exist for a possible phase transition in the SEI for all seven Li-based electrolytes and one out of four Na electrolytes. The associated critical temperatures are between $0-25^{\circ} \mathrm{C}$ for the seven $\mathrm{Li}$ electrolytes and between $50-60^{\circ} \mathrm{C}$ for the $\mathrm{Na}$ one. While no direct proof of a phase transition can be given here, the measured changes in the associated overpotential are significant. While the current publication confirms that the SEI overpotentials for Li electrodes are negligible at room temperature ${ }^{1}$ these overpotentials become dom- inant at very low temperature confirmed both by galvanostatic and impedance spectroscopy. The current study also confirms that $\mathrm{K}$ and $\mathrm{Rb}$ would possess low ionic conduction within the SEI which results in significant overpotentials. However, also $\mathrm{Na}$ has low conduction at room temperature and a much higher critical temperature above $50^{\circ} \mathrm{C}$, which places certain disadvantages compared to Li-based electrodes.

Overall, further investigation of the conduction mechanisms within the SEI and the possibility of a phase transition with a critical temperature for e.g. the SEI on graphite, would be of outmost importance for battery management systems. Additionally, assuming a zero SEI resistance in battery models would results in very little error during parameter estimation if one fits data above $T_{C}$. However, any state-of-health and state-of-charge estimator will determine incorrect parameters below $T_{C}$ and might cause significant safety issues during recharging of $\mathrm{Li}$-ion based batteries at low temperatures which would be a critical issue for the electrification of the transportation sector.

\section{Acknowledgments}

I would like to thank the reviewers for helpful comments on the manuscript. Additionally, I thank V. Wood, the Swiss National Science Foundation (grant 20PC21_15566/1) and Battronics (project NonLinSEI) for the financial support without this study would not have been possible to conduct.

\section{ORCID}

Michael Hess (D) https://orcid.org/0000-0001-9921-4735

\section{References}

1. M. Hess, "Non-linearity of the solid-electrolyte-interphase overpotential," Electrochim Acta, 244, 69 (2017).

2. M. Hess, Kinetics and stage transitions of graphite for lithium-ion batteries, $P h D$ thesis 21240, ETH Zurich, 2013, pp. 52.

3. D. Aurbach, I. Weissman, A. Zaban, and O. Chusid, "Correlation between surfacechemistry, morphology, cycling efficiency and interfacial properties of Li electrodes in solutions containing different Li salts," Electrochim Acta, 39, 51 (1994).

4. M. Gaberscek, J. Jamnik, and S. Pejovnik, "Impedance spectroscopy of a passive layer on lithium," J Electrochem Soc, 140, 308 (1993).

5. M. D. Levi and D. Aurbach, "Simultaneous measurements and modeling of the electrochemical impedance and the cyclic voltammetric characteristics of graphite electrodes doped with lithium," J. Phys. Chem. B, 101, 4630 (1997).

6. A. Zaban, E. Zinigrad, and D. Aurbach, "Impedance spectroscopy of Li electrodes. 4. A general simple model of the Li-solution interphase in polar aprotic systems," Journal of Physical Chemistry, 100, 3089 (1996).

7. M. Doyle, T. F. Fuller, and J. Newman, "Modeling of Galvanostatic Charge and Discharge of the Lithium Polymer Insertion Cell," J Electrochem Soc, 140, 1526 (1993).

8. R. V. Moshtev, Y. Geronov, and B. Puresheva, "The primary passive film on Li in SOCl2 elecrolyte solutions," J Electrochem Soc, 128, 1851 (1981).

9. F. M. Delnick, "The kinetics of charge-transfer reactions on passive lithium electrodes," J Power Sources, 26, 129 (1989).

10. E. S. Nimon, A. V. Churikov, A. V. Shirokov, A. L. Lvov, and A. N. Chuvashkin, "Ionic transport in passivating layers on the lithium electrode," J Power Sources, 44, 365 (1993).

11. R. F. Scarr, "Kinetics of solid lihium electrode in propylene carbonate," J Electrochem Soc, 117, 295 (1970).

12. Y. Geronov, F. Schwager, and R. H. Muller, "Electrochemical studies of the film formation on lithium in propylene carbonate solutions under open-circuit conditions," J Electrochem Soc, 129, 1422 (1982).

13. A. V. Churikov, "Transfer mechanism in solid-electrolyte layers on lithium: influence of temperature and polarization," Electrochim Acta, 46, 2415 (2001).

14. L. Young, Anodic oxide films, Academic Press, London and New York, 1961.

15. N. F. Mott and R. W. Gurney, Electronic processes in ionic crystals, Dover Publications 1964.

16. E. Peled, "The electrochemical behavior of alkali and alkaline earth metals in nonaqueous battery systems - the solid electrolyte interphase model," J Electrochem Soc, 126, 2047 (1979).

17. E. Peled and S. Menkin, "Review-SEI: past, present and future," J Electrochem Soc, 164, A1703 (2017).

18. G. Pistoia, M. DeRossi, and B. Scrosati, "Study of behavior of ethylene carbonate as a nonaqueous battery solvent," J Electrochem Soc, 117, 500 (1970).

19. K. Xu, "Nonaqueous liquid electrolytes for lithium-based rechargeable batteries," Chemical Reviews, 104, 4303 (2004). 
20. P. Pietsch, M. Hess, W. Ludwig, J. Eller, and V. Wood, "Combining operando synchrotron X-ray tomographic microscopy and scanning X-ray diffraction to study lithium ion batteries," Scientific Reports, 6, 27994 (2016).

21. L. O. Valoen and J. N. Reimers, "Transport properties of LiPF6-based Li-ion battery electrolytes," J Electrochem Soc, 152, A882 (2005).

22. Y. Zhu, F. Wang, L. Liu, S. Xiao, Y. Yang, and Y. Wu, "Cheap glass fiber mats as a matrix of gel polymer electrolytes for lithium ion batteries," Scientific Reports, $\mathbf{3}$, 3187 (2013).

23. S. I. Lee, U. H. Jung, Y. S. Kim, M. H. Kim, D. J. Ahn, and H. S. Chun, "A study of electrochemical kinetics of lithium ion in organic electrolytes, Korean" J Chem Eng, 19, 638 (2002)

24. P. B. Balbuena and Y. Wang, Lithium-Ion Batteries: Solid-Electrolyte Interphase, Imperial College Press 2004

25. E. J. Plichta and W. K. Behl, "A low-temperature electrolyte for lithium and lithiumion batteries," J Power Sources, 88, 192 (2000).

26. Merck Chemicals AG, Materials for Li-ion batteries and double-layer capacitors, SelectiLyte materials, 2009, pp. 1.
27. M. Dahbi, F. Ghamouss, F. Tran-Van, D. Lemordant, and M. Anouti, "Comparative study of EC/DMC LiTFSI and LiPF6 electrolytes for electrochemical storage," $J$ Power Sources, 196, 9743 (2011).

28. J. Barthel, H. J. Gores, and G. Schmeer, "The temperature dependence of the properties of electrolyte solutions. III. Conductance of various salts at high concentrations in propylene carbonate at temperatures from $-45^{\prime} \mathrm{C}$ to +25 ' C," Berichte Der Bunsen-Gesellschaft-Physical Chemistry Chemical Physics, 83, 911 (1979).

29. M. S. Ding, K. Xu, and T. R. Jow, "Conductivity and viscosity of PC-DEC and PC-EC solutions of LiBOB," J Electrochem Soc, 152, A132 (2005).

30. A. Ponrouch, E. Marchante, M. Courty, J. -M. Tarascon, and M. Rosa Palacin, "In search of an optimized electrolyte for Na-ion batteries," Energy \& Environmental Science, 5, 8572 (2012).

31. M. S. Ding, K. Xu, and T. R. Jow, "Liquid-solid phase diagrams of binary carbonates for lithium batteries," J Electrochem Soc, 147, 1688 (2000).

32. P. Verma, P. Maire, and P. Novák, "A review of the features and analyses of the solid electrolyte interphase in Li-ion batteries," Electrochim Acta, 55, 6332 (2010). 